\title{
The influence of the coal mining process on the state of the earth's surface in the district of the block
}

\author{
Alexander Abramovich ${ }^{1, *}$ Yuri Stepanov ${ }^{2}$, and Juraj Janocko ${ }^{3}$ \\ ${ }^{1}$ Branch of T. F. Gorbachev Kuzbass State Technical University in Prokopievsk, 653039, 19a \\ Nogradskaya str., Prokopievsk, Kemerovo region, Russian Federation \\ ${ }^{2}$ Kemerovo State University (KemSU), 650000, 6 Krasnaya str., Kemerovo, Kemerovo region, \\ Russian Federation \\ ${ }^{3}$ Technical University Košice, Faculty BERG, Letná 9, 04001 Košice, Slovakia
}

\begin{abstract}
This article considers the prerequisites to the development of technologies and a method of computer analysis of the influence of the coal mining process on the state of the earth's surface in the district of the breakage face. The paper presents an algorithm for the implementation of preparatory works for analysis of the influence of coal mining on the state of the earth's surface in the district of the block in the form of activity diagram, as well as the tools that are necessary for this analysis are considered. The technologies of 3D modeling of massif by means of FreeCAD are considered, and the analysis of solids formation methods, characterizing rock formation, is carried out. For more accurate calculations and analysis, the finite element model of massif must be built with detail, that is, to break down solids into smaller elements. The article represents a technology, the application of which will be implemented in cooperation with rock geographic information systems, which be capable of a detail analysis and assessment of the impact of coal mining on the surface within the second working.
\end{abstract}

\section{Introduction}

At present, there is an increase in volume of sand mining, which implies upgrade of equipment to a more high-tech one, often allowing remote monitoring and control of its engineering status and the state of technical processes with which it is directly connected. Installation of new, more productive equipment leads not only to a swell of output, but also to safety improving at enterprises extracting valuable minerals by inside or surface mining. Safety in such enterprises includes the analysis and assessment of various factors in the event of which emergencies arise. Development of mines districts, which are the most dangerous in terms of rock bumps characteristics and emissions, which can be included to the issues of stress-strain state of the massif, can be attributed to one of such factors. There are several methods of various types for conducting research of massif and detecting of

\footnotetext{
* Corresponding author: abramovich_sanja@rambler.ru
} 
allotments that are burst-prone and prone to sudden rushes. Among them are methods of direct monitoring of the massif and computer-based simulation methods. Computer-based simulation methods, as well as direct monitoring methods cannot provide accurate results, for this reason, to obtain more reliable information about the state of mines, it is necessary to combine existing methods of monitoring and modeling the stress-strain state of massif.

Oftentimes the analysis and assessment of the state of mine workings are carried out in a static form, which entertain a possibility of obtaining equivocal calculation data due to the redistribution of stress-strain state within the longwall face, consequently, for more accurate calculations of the condition of the stress-strain state in computer modeling, it is needed to use continuous monitoring of mines, which is based on continuous control of entries and the breakage face. The frequency of modeling and appraisal of the stress-strain state thickens with increase of sand mining depth. During mining extraction of mineral deposits rock pressure can be redistributed within the breakage face and nearby mine workings. To increase the accuracy of obtained results, it is necessary to take into account the previous state of the massif. Thus, there is a need to conduct research in dynamics of rock destruction by events or in time, in so much as the process of rock formation relaxation is often ignored.

A wide variety of computer programs are used to conduct computer modeling and analysis of stress-strain state of rock formation. To solve the problems of this class, it is reasonable to apply information models and technologies involving geographic information systems for the subsequent high-quality control of technological processes and prevention of emergency situations. The task of predicting the dynamic caving of rock massif during second working is still relevant, since it is described by a set of models of various physical nature and cannot be solved by analytical methods.

\section{Materials and methods}

Currently, there is no ready-made solution for analysis and modeling the influence of the coal mining process on the state of the earth's surface in the district of the block. To conduct research of the influence of factors, arising during coal mining, on the state of the surface of the block, and visual modeling, and also stress-strain state calculations, Geological and Mining Information System (GGIS) and CAD systems can be used as tools. The use of GGIS in this task is necessary for visualization on maps of surface of the earth and modeling of potential zones of deformation of the earth's surface within the block.

For 3D modeling of mines and analysis of stress-strain state, in particular roof displacement, it is needed to use FreeCAD based on a previous analysis [1]. QGIS will be used as GGIS in this task, since this GIS is freely distributable software. 3D - Modeling of mines is proposed to be carried out on the basis of the layout of coal enterprises. The layout, as a rule, is built in AutoCAD, therefore, to solve the problem of more accurate modeling of blocks and underground workings, it will also be necessary [1-11].

The impact analysis of the coal mining process on the state of the earth's surface in the district of the block presupposes the implementation of preparatory works for further computer modeling, which are presented in Figure 1 in the form of activity diagram.

Thus, there is a need to use a method of calculating the parameters of the stress-strain state of rock massif, including the setup procedure of algorithm based on historical data, to minimise deviations of the evaluated values from the measured ones. 


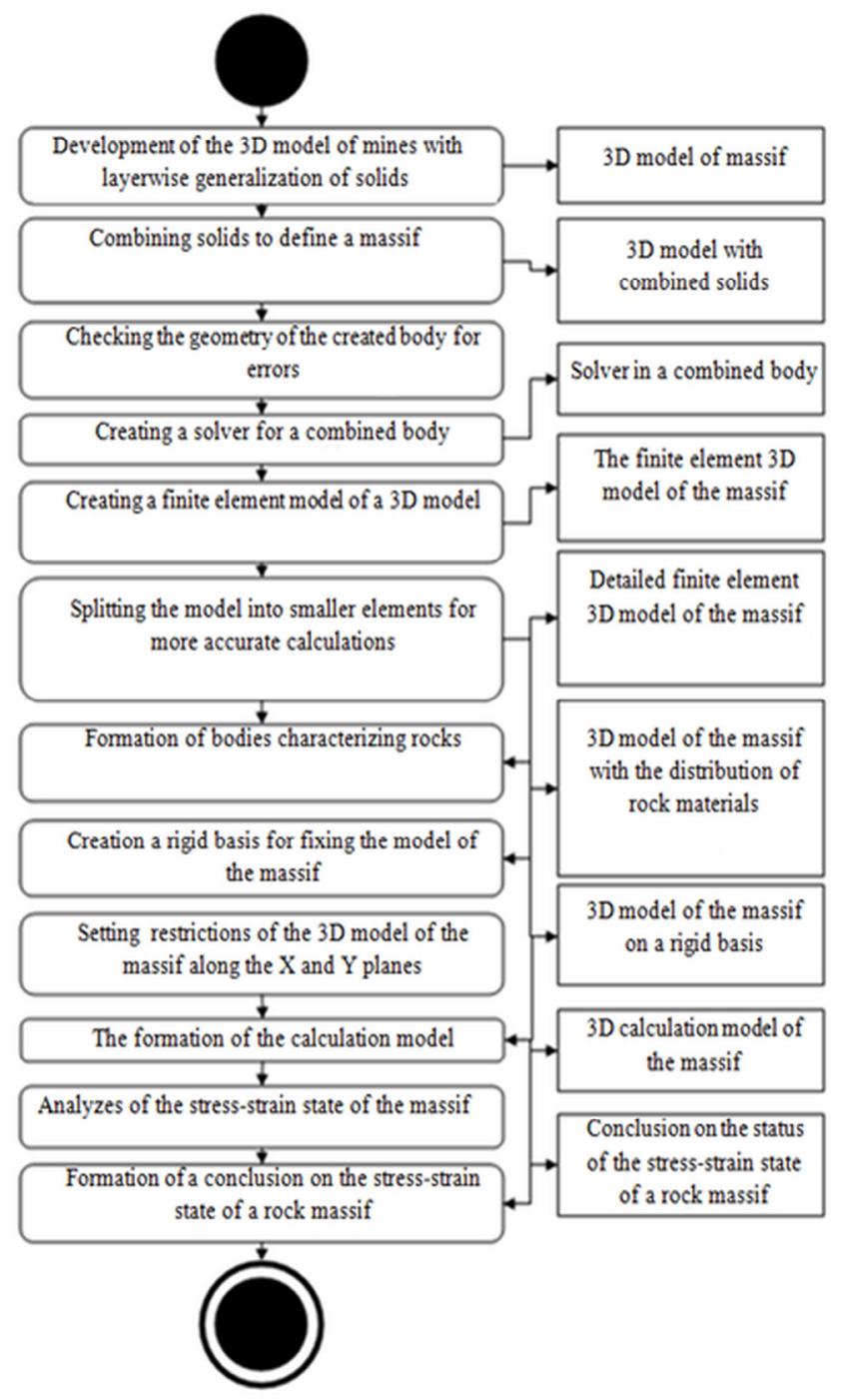

Fig. 1. An algorithm to the analysis of the state of the earth's surface in the district of mining.

\section{Realization}

To form a more precise 3D model of the massif with the application of mines and breakage face, as well as determining the creation rules of bodies characterizing rock formation, several existing technologies can be applied:

1. Determining the rules for the formation of bodies characterizing rock formation within the massif, with the use of stratigraphic columns, as in Fig. 2. In this case, the database is designed to store attribute and geospatial data of the rock slices. The formats of electronic classifiers are selected.

2. On the basis of spatial and attribute data, a computer model of mines with projections of drill-holes on electronic map can be built. Determining the rules for the formation of bodies characterizing rock formation within the massif, using the capabilities of FreeCAD. 


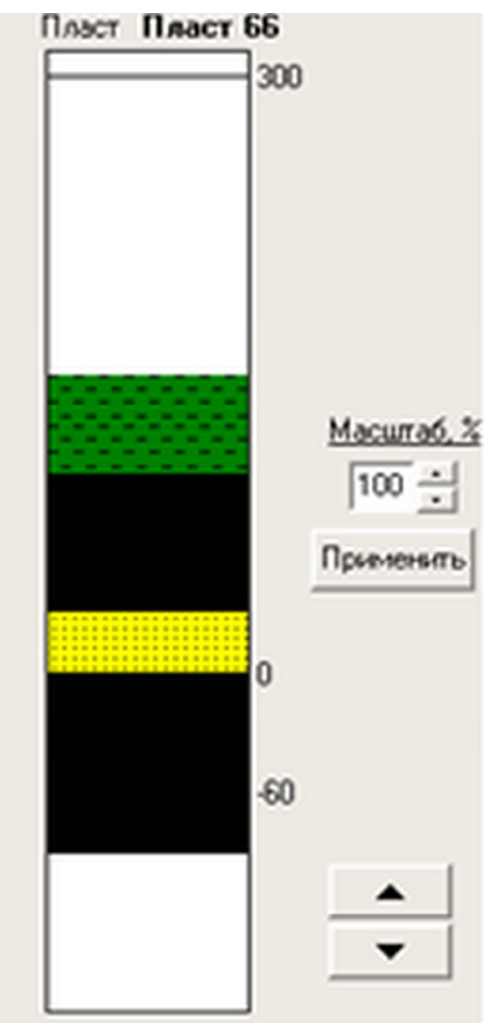

Fig. 2. Stratigraphic column of rock massif.

Comparing the two methods of determining the creation rules of bodies characterizing rock formation, the most accurate results will be ensured by the use of CAD systems, provided a more detailed 3D modeling of the massif. In future, it is planned to consider the possibility of determining the characteristic of rock formation for the finite elements of the 3D model.

An example of a 3D model of the block was built to conduct an analysis. By applying several operations to detail the obtained 3D model with meshing of finite elements, we get more accurate results while performing calculations of stress-strain state, in particular roof displacement of mines, which can work on the state of the earth's surface within the blocks [12]. A $3 \mathrm{D}$ model of underground working with detailing of the finite elements mesh is shown in Figure 3. 


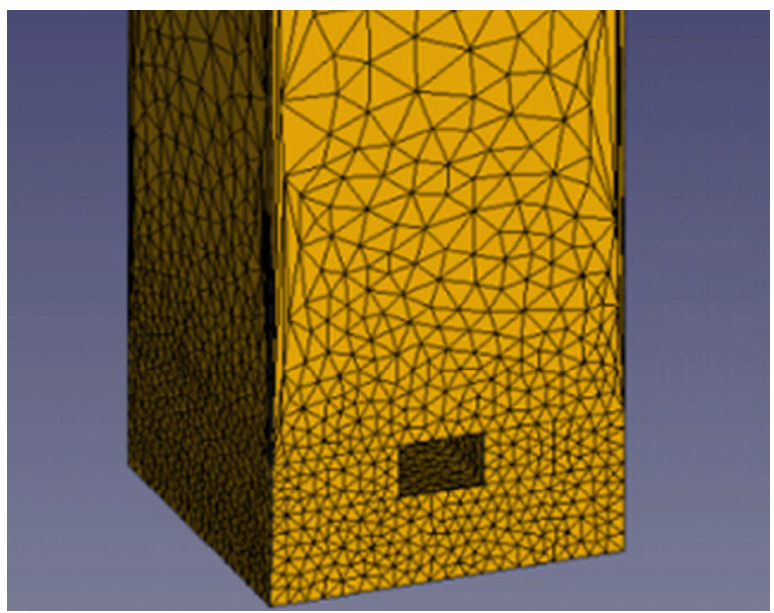

Fig. 3. A 3D model of the block with the finite elements mesh.

Based on the obtained 3D model, we carry out calculations and analysis according to the essentials: the displacement of the 3D-model along the axes $\mathrm{X}, \mathrm{Y}, \mathrm{Z}$; the maximum stressstrain state; the minimum stress-strain state; as well as the maximum shear stress, on the basis of which we can draw conclusions about the stress-strain state of the massif. The outcomes of simulation modelling are presented in the form of stress fields or displacements in the investigated volume of rock massif or in the form of graphs using custom editors or in line-of-business applications. The work window with the results of the calculation of full vertical intensities in the finite elements is presented in Figure 4.

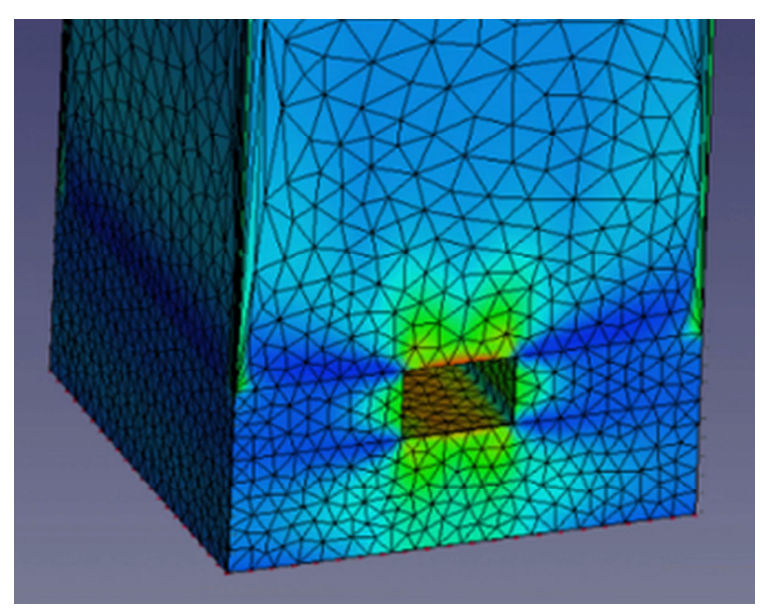

Fig. 4. The result of stress-strain state calculation in the district of working.

\section{Conclusion}

As a result of the work, a technology of conducting a static analysis of stress-strain state of blocks using FreeCAD was developed. Tools for solving the problem of underground modeling of stress-strain state of rock formation, including for the analysis of rock displacements in dynamics, were identified in the work. It allows to track the redistribution of stress-strain state in the district of breakage face. This technology is required for further 
researches of influence of the coal mining process on the state of the earth's surface in the district of breakage face. This will allow to conduct research of the impact of subsurface mining on the state of the earth's surface, as well as to analyze blocks and mines and increase the safety of underground and opencast mining work.

The problem of visualizing the change of rock massif state over time is solved by displaying to the screen a sequence of static images (frames), which are a set of animated surfaces.

\section{References}

1. A. Abramovich, Yu. Stepanov, J. of E3S Web of Conferences, 134, 01001 (2019)

2. M. Satya, O. Anurag, M. Sachin, Nat. Conf. OSGIS-2015, 150 (2015)

3. C. Zhao, Y. Zhang, G. Zhang, J. Li, S. Ma,Sensors, 17, 1044 (2017)

4. J. Doherty, A. Hasan, G. Suazo, A. Fury,Can. Geotech. J. 52, 1901 (2015)

5. E. Lawson, D. Tesarik, M. Larson, H. Abraham, Int. Conf. GCM. 35, 26 (2016)

6. Y. Mustafa, A. Ahmet, O. Muharrem, K. Bayram, Y. Hayati, Int. J. E.Res.Tech. 7, 199 (2018)

7. M. Larson, D. Tesarik,J.Seymour, R. Rains, Inf. Circ. 151, 253 (2000)

8. Z. Zhang, J. Bai, Y. Chen, S. Yan, Int. J. Rock Mech. Min. Sci., 80, 1 (2015)

9. Y. Lu, W. Yang, J. of Central South. Univer. 20, 1397 (2013)

10. A. Chanyshev, I. Abdulin, J. of Mining Sci. 50, 18 (2014)

11. V. Vaziri, J. Hamidi, A. Sayadi, Environ. Earth Sci. 77, 1 (2018)

12. S. Kostyuk, A. Gegreen, V. Meljnik, M. Lupeey, E3S Web Conf., 21, 01035 (2017) 